\title{
Implementation of an Electric Vehicle Test Bed Controlled by a Virtual Power Plant for Contributing to Regulating Power Reserves
}

Marra, Francesco; Sacchetti, Dario; Pedersen, Anders Bro; Andersen, Peter Bach; Træholt, Chresten; Larsen, Esben

\section{Published in:}

Proceedings of the 2012 IEEE Power \& Energy Society General Meeting

Link to article, DOI:

10.1109/PESGM.2012.6345269

Publication date:

2012

Link back to DTU Orbit

Citation (APA):

Marra, F., Sacchetti, D., Pedersen, A. B., Andersen, P. B., Træholt, C., \& Larsen, E. (2012). Implementation of an Electric Vehicle Test Bed Controlled by a Virtual Power Plant for Contributing to Regulating Power Reserves. In Proceedings of the 2012 IEEE Power \& Energy Society General Meeting IEEE.

https://doi.org/10.1109/PESGM.2012.6345269

\section{General rights}

Copyright and moral rights for the publications made accessible in the public portal are retained by the authors and/or other copyright owners and it is a condition of accessing publications that users recognise and abide by the legal requirements associated with these rights.

- Users may download and print one copy of any publication from the public portal for the purpose of private study or research.

- You may not further distribute the material or use it for any profit-making activity or commercial gain

- You may freely distribute the URL identifying the publication in the public portal 


\title{
Implementation of an Electric Vehicle Test Bed Controlled by a Virtual Power Plant for Contributing to Regulating Power Reserves
}

\author{
F. Marra, Student Member, IEEE, D. Sacchetti, A. B. Pedersen, P. B. Andersen, C. Træholt, \\ and E. Larsen
}

\begin{abstract}
With the increased focus on Electric Vehicles (EV) research and the potential benefits they bring for smart grid applications, there is a growing need for an evaluation platform connected to the electricity grid. This paper addresses the design of an EV test bed, which using real EV components and communication interfaces, is able to respond in real-time to smart grid control signals. The $\mathrm{EV}$ test bed is equipped with a Lithium-ion battery pack, a Battery Management System (BMS), a charger and a Vehicle-to-Grid (V2G) unit for feeding power back to the grid. The designed solution serves as a multifunctional grid-interactive EV, which a Virtual Power Plant (VPP) or a generic EV coordinator could use for testing different control strategies, such as $\mathrm{EV}$ contribution to regulating power reserves. The EV coordination is realized using the IEC 61850 modeling standard in the communication. Regulating power requests from the Danish TSO are used as a proof-of-concept, to demonstrate the $\mathrm{EV}$ test bed power response. Test results have proven the capability to respond to frequent power control requests and they reveal the potential $\mathrm{EV}$ ability for contributing to regulating power reserves.
\end{abstract}

Index Terms - Electric vehicles, Test Bed, Regulating power, Virtual Power Plant

\section{INTRODUCTION}

$\mathrm{T}$ HE Electric Vehicles and Plug-in Hybrid EV (PHEV) are expected to play an important role in the future power system. Within smart grids research, electrical transportation has a complementary role in the overall system management of energy and power [1]; moreover the European target on reducing $\mathrm{CO}_{2}$ emissions and increasing penetration of renewable energy are among the major drivers for the research [2].

The energy storage capability is the key factor for smart grid applications of EV in power system. When parked and plugged into the grid, EV are expected to either charge intelligently, or discharge feeding power back to the grid [3]. In the latter case, EV would enter a mode known as Vehicleto-Grid (V2G), permitting the provision of several grid

This work was in part funded through the EDISON project, a research project of the public Danish transmission system operator Energinet.dk's research program FORSKEL, (Project Number 081216).

F. Marra, D. Sacchetti, A. B. Pedersen, P. B. Andersen, C. Træholt, and E. Larsen are with the Centre for Electric Technology, Department of Electrical Engineering, Technical University of Denmark, 2800 Kgs. Lyngby, Denmark (e-mail: fm@elektro.dtu.dk). services [4]. In general, if the individual $\mathrm{EV}$ can be intelligently managed, a large number of such vehicles can become an asset in the future power system. The charging process could be controlled by modulating the charging power, as well as the discharging process, by enabling the V2G mode when there is a need from the grid [5]. Many projects are addressing the aforementioned EV operation, as coordinated charging using different simulation tools. In [6], the authors analyze, through dynamic simulations, the potential daily profits for EV users, with the provision of regulating power. In [7], the authors studied the benefits offered by EV for facilitating the integration of large scale wind power in Denmark; EV fleets are modeled in a simulation platform as storage units when charging or as small generators during V2G operation. Galus et al. in [8] presented a method for tracking secondary frequency control using groups of PHEV and a simulation platform to simulate an EV aggregator.

The participation of $\mathrm{EV}$ in regulating power schemes is possible using an aggregation entity for EV coordination. This is done in the Danish EDISON project [9]-[10], where the contributors proposed a centralized coordination solution for an efficient integration of EV in the power system. The aggregation technology is based on the Virtual Power Plant (VPP) concept [11], where the Edison VPP is the EV coordinator.

Evaluating the contribution of an EV for regulating power reserves in a VPP framework, where a huge amount of communication and hardware interfaces are involved, gives raise to the need of new grid-interactive evaluation platform.

This paper describes the implementation phases of an EV test bed, working under the coordination of a VPP and contributing in regulating power reserves, as secondary frequency control [12]. A real regulating power request from the Danish Transmission System Operator (TSO) is processed by the VPP and sent in form of a charging/discharging power schedule to the EV test bed.

Test results performed using the EV test bed show that an $\mathrm{EV}$ is in fact capable of real-time communication with a VPP and can quickly react to contribute to grid power reserves.

\section{ELECTRIC VEHICLES FOR SMART GRIDS}

The interaction between EV and the electric power system is only possible if the vehicles can connect to the electrical 
grid for charging.

An effective interaction between EV and grid requires the combinations of different factors such as:

- Grid interactive vehicle architectures;

- Controllable charging/discharging operation;

\section{A. Electric vehicle architectures}

Among different types of hybrid electric vehicles and pure electric vehicles, a general distinction is based on their ability to plug-in. In this work, non plug-in hybrid vehicles will be disregarded, as an interconnection with the grid is not possible.

This section lists the system architectures capable of charging using the grid [13]. There are mainly two classes of plug-in EV: plug-in hybrid EV (PHEV) and battery-powered EV. An overview on the different architectures is depicted in Fig. 1.

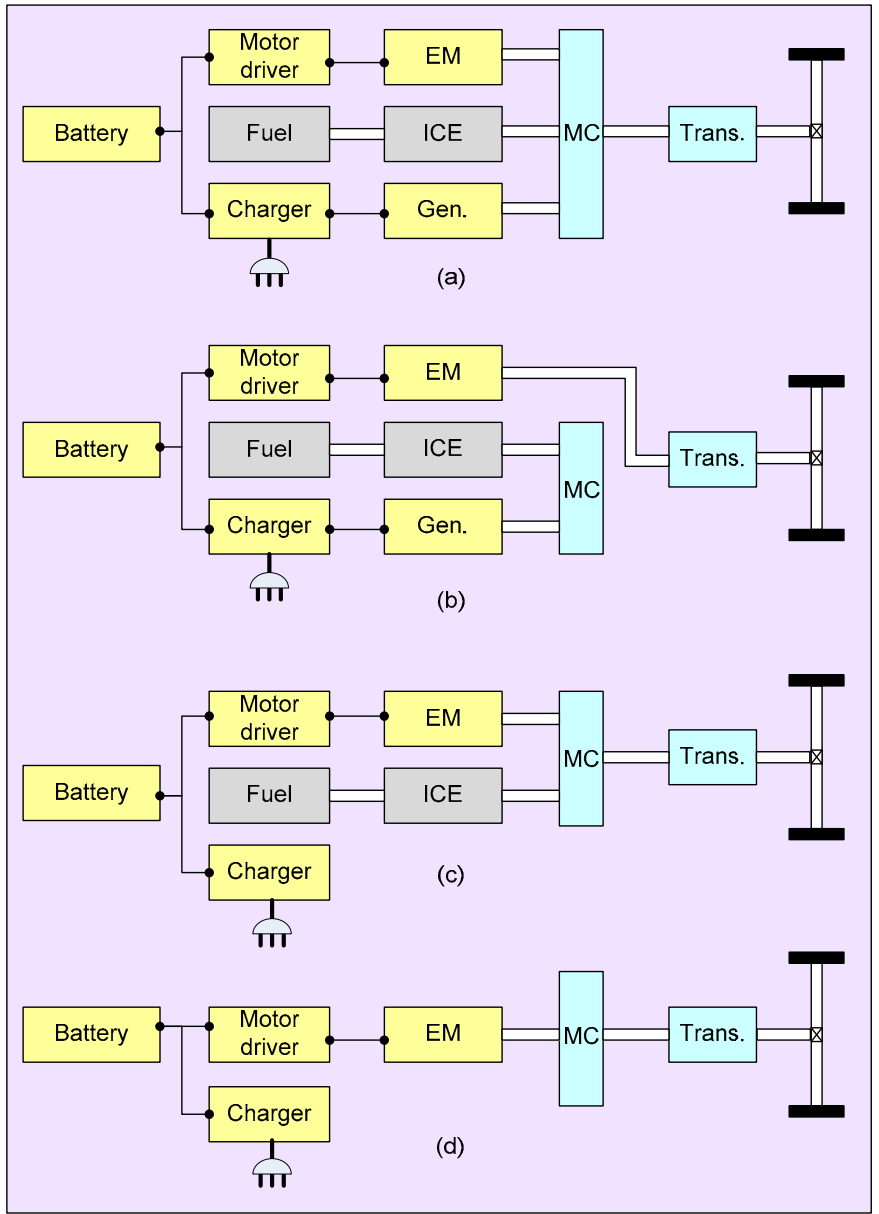

Fig. 1. Plug-in Electric Vehicles system architectures. (a) Series-parallel hybrid EV. (b) Series hybrid EV. (c) Parallel hybrid EV. (d) Battery-powered EV far:

In the PHEV class, three variants have been developed so

- $\quad$ Series-parallel hybrid

- Series hybrid

- Parallel hybrid
The main difference among the topologies is the drive system used and the interconnection of its components, before the power is transferred to the wheels.

In the series-parallel hybrid vehicle, Fig. 1 (a), the system is designed to operate both in a series or parallel configuration. The reconfigurable system is made possible by the use of a planetary gear, which is the mechanical coupling (MC) for the three machines. In the series hybrid vehicle, Fig. 1 (b), the electric traction system and Internal Combustion Engine (ICE) system operate in a series connection. In sequence, the ICE is coupled with a generator (Gen.) which generates the electric power for recharging the battery, the battery then supplies an electric motor driver to transfer power to wheels. In the parallel hybrid vehicle, Fig. 1 (c), the ICE and electric motor (EM) operate in parallel mode, where the ICE supports the electric traction at certain points of the driving pattern, e.g. when higher power is needed to the wheels.

In the battery-powered EV class, Fig. 1 (d), the drive system is realized using only an electric motor and a motor driver. Therefore the only energy source is the battery pack.

In this work a battery-powered EV is the architecture chosen for the EV test bed implementation.

\section{B. Controllable charging/discharging operation}

All plug-in EV are able to absorb power from the grid while charging their battery packs. The controlled charging or discharging (V2G) process can be achieved using different infrastructure concepts, such as home charging or public charging stations [14]. According to the IEC 61851 standard [15], the most common power rates for domestic and public charging are depicted in Table I.

TABLE I

CHARGING POWER RATES

\begin{tabular}{cccc}
\hline AC current & AC voltage & Grid connection & Power \\
\hline $10 \mathrm{~A}$ & $230 \mathrm{~V}$ & single phase & $2.3 \mathrm{~kW}$ \\
$16 \mathrm{~A}$ & $230 \mathrm{~V}$ & single phase & $3.7 \mathrm{~kW}$ \\
$32 \mathrm{~A}$ & $230 \mathrm{~V}$ & single phase & $7.4 \mathrm{~kW}$ \\
$16 \mathrm{~A}$ & $400 \mathrm{~V}$ & three-phase & $11 \mathrm{~kW}$ \\
$32 \mathrm{~A}$ & $400 \mathrm{~V}$ & three-phase & $22 \mathrm{~kW}$ \\
\hline
\end{tabular}

All power rates, regardless of charging or discharging, are characterized by an AC current, usually $16 \mathrm{~A}$ or $32 \mathrm{~A}$, and based on the grid connection type, single-phase or three-phase.

In this work a charging/discharging power rate of $\pm 2.3 \mathrm{~kW}$ is used for the experimental validation.

\section{Planned EV test bed operation with Virtual Power Plant}

The EV system architecture is planned to respond to different control signals from a centralized EV coordinator.

The control signals for the vehicles can be generated by a VPP and based on different variables such as the power system frequency, the market spot price and others.

In this paper, the centralized control concept for EV fleet management as described by Binding et al. in [10] is used as a study framework. The EV test bed operation is planned within the VPP framework depicted in Fig. 2. Different interfaces have been defined to establish communication between the Edison VPP and other entities in the architecture. While a 
generic VPP can aggregate and control various distributed energy resources (DERs), e.g. combined heat and power units (CHPs), PV plants, wind turbines, medium/large consumers, other power units and smart houses, in this paper, only EV are considered.

An interface with the TSO is defined to receive the activation commands for accepted regulating power reserves contracts.

An interface with the Distribution System Operator (DSO) is also defined to collect the grid status for the location of every connected EV. Grid constraints are considered at this interface, to ensure that the charging/discharging operation complies with power quality issues. In addition, the metering information for accounting is also collected via the DSO interface.

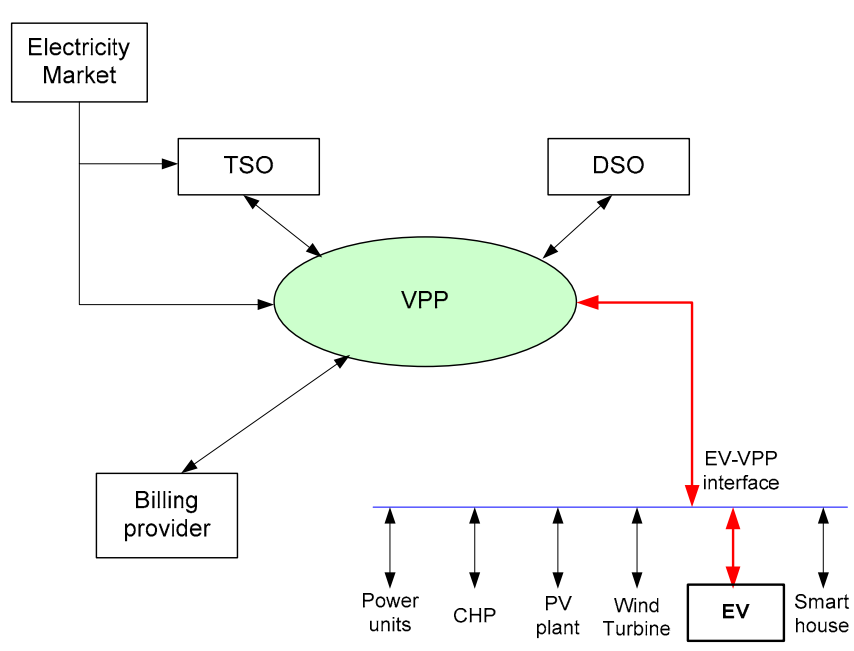

Fig. 2. EV test bed operation in a Virtual Power Plant framework

The transaction interface with a billing provider is used to perform billing to the resources providing regulating services.

In this paper, the EV-VPP interface is implemented to establish communication between the VPP and the EV test bed. The control requests for the EV test bed are generated from the VPP, based on the grid needs of regulating power reserves of the TSO.

\section{Test Bed ImPLEMENTATION}

Designing an EV test bed for testing the potential EV operation with a VPP was performed in two phases:

- Planning the EV test bed architecture

- Dimensioning the EV components

\section{A. Planning the EV test bed architecture}

With reference to the EV architectures described in Section II, a battery-powered EV architecture was the choice for the $\mathrm{EV}$ test bed implementation. The main reasons for choosing this architecture is that with a pure battery EV, zero emissions can be achieved during driving [16], while grid interaction is more meaningful, due to a larger storage capacity.

In a battery-EV the following components can be considered:
- a battery pack

- a battery charger

- a BMS

- a three-phase motor driver

- $\quad$ an electric motor

For the scope of the study, the three-phase motor driver and the electric motor are not needed, therefore these two components were not considered in the development.

Since with the architecture of Fig. 1 (d), the V2G operation is not possible, this was enhanced by adding a $\mathrm{V} 2 \mathrm{G}$ unit which could operate in a complementary way to the charger. The implemented EV test bed architecture is shown Fig. 3.

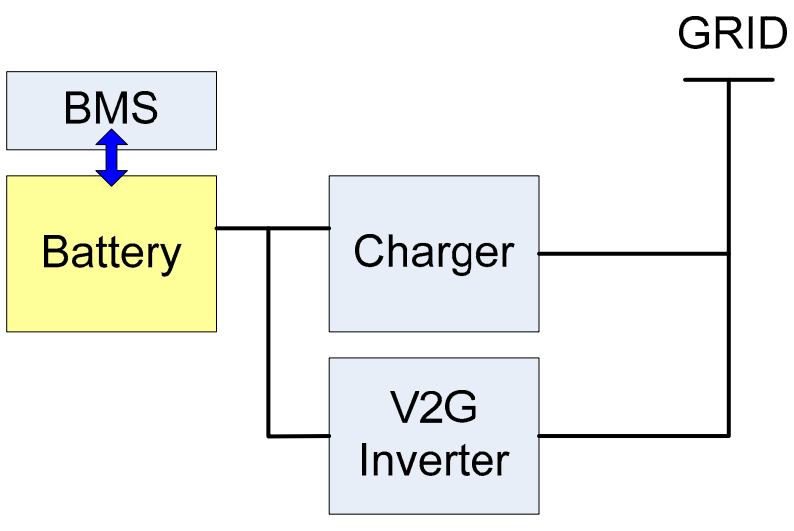

Fig. 3. EV test bed architecture

The battery pack is interfaced to a battery management system (BMS), which monitors its status.

The charger is designed as an $\mathrm{AC} / \mathrm{DC}$ converter, directly connected to the main grid, by means of a three phase cable connection; while the $\mathrm{V} 2 \mathrm{G}$ unit is made of a single phase $\mathrm{DC} / \mathrm{AC}$ inverter.

It is worth noticing that, since the aim of the EV test bed is to emulate a real $\mathrm{EV}$ connected to the grid, all $\mathrm{EV}$ components were dimensioned according to realistic EV energy and power levels.

\section{B. EV test bed components}

The design of the battery pack took into account the following requirements:

- Common designs of battery-EV [17][18]

- V2G operation requirement

The choice of a battery technology to use for the test bed was based on the analysis of current market trends for EV. Some consulting companies, e.g. Frost \& Sullivan [19], foresee more than $70 \%$ of EV in 2015 to be powered by lithium-ion (Li-ion) batteries. Compared to other battery technologies, Li-ion batteries offer a greater energy-to-weight ratio, greater power levels and low self-discharge when not in use [16]. For the reasons mentioned, a Li-ion battery was the choice for the EV test bed.

The electrical features of the battery pack were chosen considering common designs of EV battery packs. Generally 
battery-EV have battery pack voltages in the range of 300$400 \mathrm{~V}$ and a battery capacity of at least $10-15 \mathrm{kWh}$. A battery pack was designed integrating $110 \mathrm{Li}$-ion series connected battery cells, which leads to a total nominal pack voltage, $V_{p a c k}$, of $363 \mathrm{~V}$. Each cell has nominal voltage $V_{n}$, of $3.3 \mathrm{~V}$ and nominal capacity $C_{n}$, of $40 \mathrm{Ah}$.

Based on the nominal parameters, the following expression is valid for calculating the nominal battery energy:

$$
E_{n}=V_{\text {pack }} \cdot C_{n}=N \cdot V_{n} \cdot C_{n}
$$

where $N$ is the number of cells.

The requirement of $\mathrm{V} 2 \mathrm{G}$ operation, a DC/AC power converter with input DC voltage in the range of $250-500 \mathrm{~V}$ was used. The rated output power of the V2G inverter is about $4 \mathrm{~kW}$, which leads to a maximum generated AC current of around $16 \mathrm{~A}$. The $\mathrm{V} 2 \mathrm{G}$ inverter is also equipped with an internal transformer, which serves as galvanic isolation.

A battery management system (BMS) is linked to the battery pack. The main function of the BMS is to ensure a safe operation of the battery pack during charging or V2G operation. It estimates the SOC information which is used by VPP and monitors the battery voltage, current and temperature.

The charger was designed as a single-phase AC/DC. The output voltage $V_{d c}$ was dimensioned using the empirical formula shown below, according to [20]:

$$
V_{d c}=1.25 \cdot V_{p a c k}=453 \mathrm{~V}
$$

The current $I_{d c}$ on the battery side is dimensioned of $10 \mathrm{~A}$ at full load, which leads a charging power of about $4.5 \mathrm{~kW}$.

The implemented test bed with integrated EV components is depicted in Fig. 4.

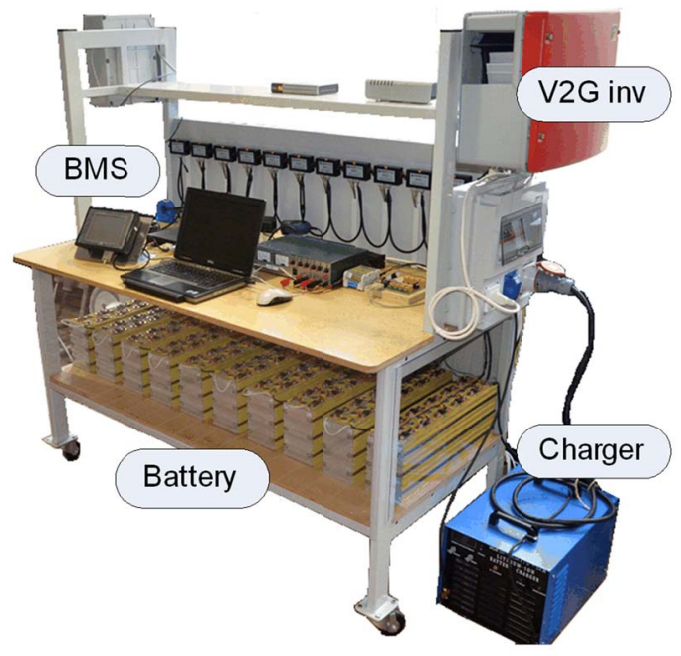

Fig. 4. EV test bed

\section{COMMUNiCATION AND CONTROL WITH VPP}

As previously mentioned, the EV test bed was designed to operate as part of a centralized aggregation framework, under the direct control of a VPP, as described in [21]. For the purpose of future research, it will be possible, in any case, to adapt the software system in order to e.g. test decentralized control schemes.

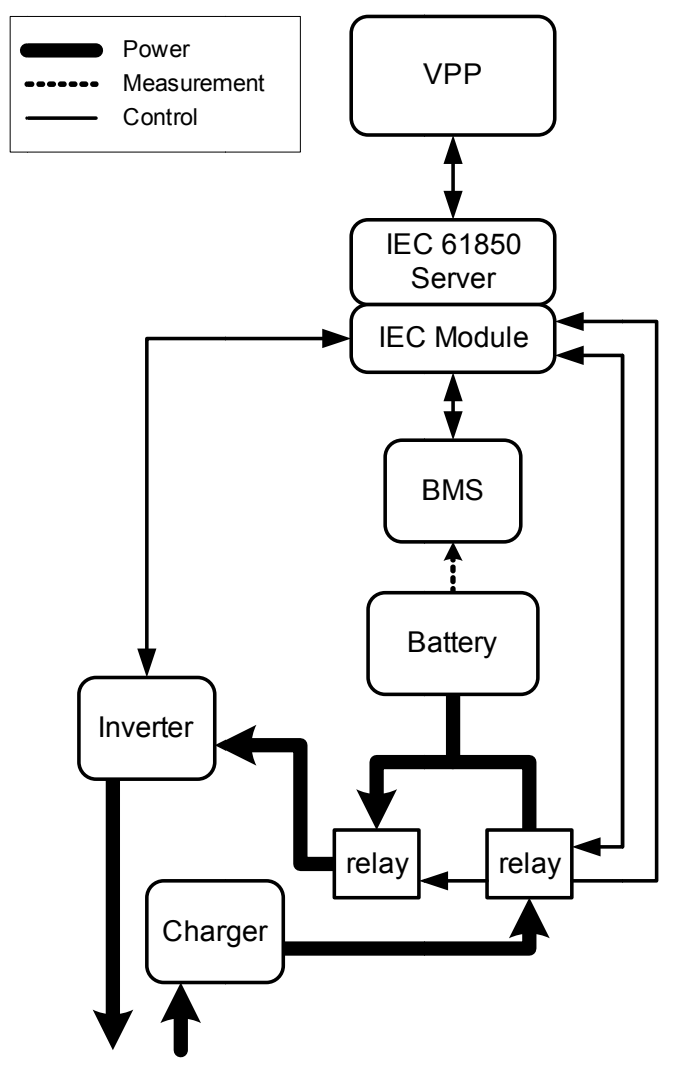

Fig. 5. EV test bed communication and control architecture

To facilitate centralized coordination, the VPP-to-EV interface was implemented in accordance with the communication and control architecture depicted in Fig. 5.

The communication is based on the well-established IEC 61850 standard [22]. As an academic exercise and in the attempt to promote the use of existing web standards in power system communication, the IEC 61850 standard was mapped to HTTP/REST. This work was presented in details in [23].

The VPP used for this paper was designed by Pedersen et al. [23] and has been used for generating and sending power schedules, in response to the requirements for regulating power reserves specified by the TSO.

Though used for an EV test bed in this case, these schedules are simply based on positive/negative power requests with an associated time stamp. For this reason, they are potentially applicable to any type of Distributed Energy Resource (DER) [24]. 


\section{A. IEC 61850 Server and Module}

The server, which was developed in compliance with the IEC 61850 standard, is designed based on a modular plug-in architecture, in order to facilitate an easier adaptation and installation of new devices of virtually any type [23].

A device specific plug-in, or IEC Module, was implemented, in order to enable direct control of the test bed from the VPP, as well as to facilitate the collection of battery status information along with any other measurements.

Because the charger and inverter are two separate pieces of hardware connected to the same battery, an algorithm was written into the plug-in module to guarantee the mutuallyexclusive operation of the connecting relays. This prevents the simultaneous operation of both devices.

Another communication link is established between software plug-in and the BMS to extract the state-of-charge (SOC) information from the battery.

\section{B. Charging}

As indicated by Fig. 6, there is no direct control link between the IEC Module and the charger; this is because the charger has not communication interface for remote control. For the purpose of this paper, the charger is fixed to a fixed power rate and is coupled or decoupled from the battery by means of a DC relay, which is controlled via RS232, as illustrated in Fig..

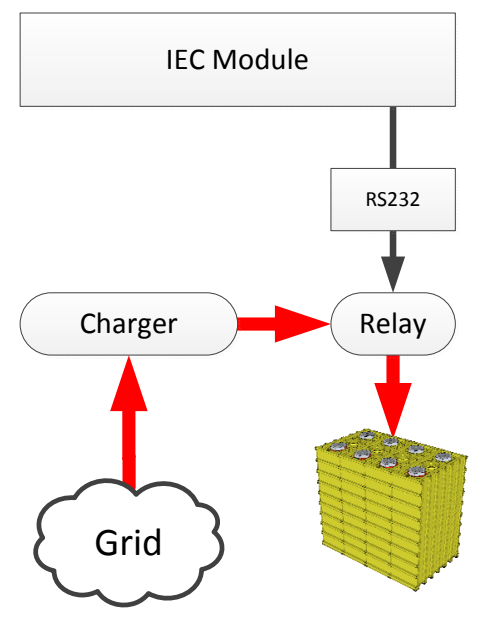

Fig. 6. Charging communication in detail

As previously mentioned, the charger and inverter are both connected to the battery pack using two mutually exclusive relays. In order to ensure that the devices have exclusive "access" to the battery, a simple timing scheme was used in the IEC Module. As depicted in Fig., a time gap was added between two switching events to ensure a safe transition.

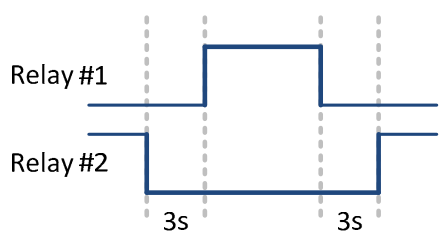

Fig. 7. Relay timing scheme

\section{C. $V 2 G$}

The coupling of the V2G inverter is achieved by means of an identical DC relay as for the charger. Under V2G operation, the generated power level is controllable and this is managed through an attached communication hub. The same hub implements an HTTP/JSON web interface. A more detailed illustration of the V2G architecture used for the EV test bed is depicted in Fig. 8.

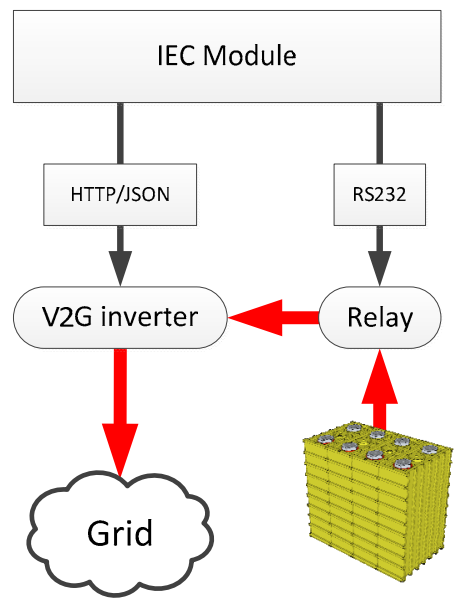

Fig. 8. V2G communication in detail

\section{Battery Status Information}

The real-time status of the battery is monitored by the BMS. The BMS information is acquired by the IEC Module using RS485 based serial communication link. By means of this link, all battery data can be extracted as a set of values and made available to the VPP via IEC 61850 for detailed monitoring. The set of values includes:

- Battery pack voltage

- Current

- State of charge

- Temperature in different areas of the battery pack

- Remaining energy and single cell voltages

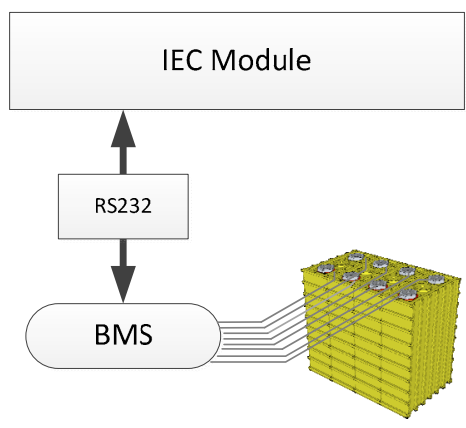

Fig. 9. BMS communication in detail

The BMS comes equipped with an RS232 port for remote monitoring of the battery pack, as well as controlling various limits/alarms. Connected to the BMS are a series of sensors, which connection are depicted as a series of smaller wires in Fig.. 


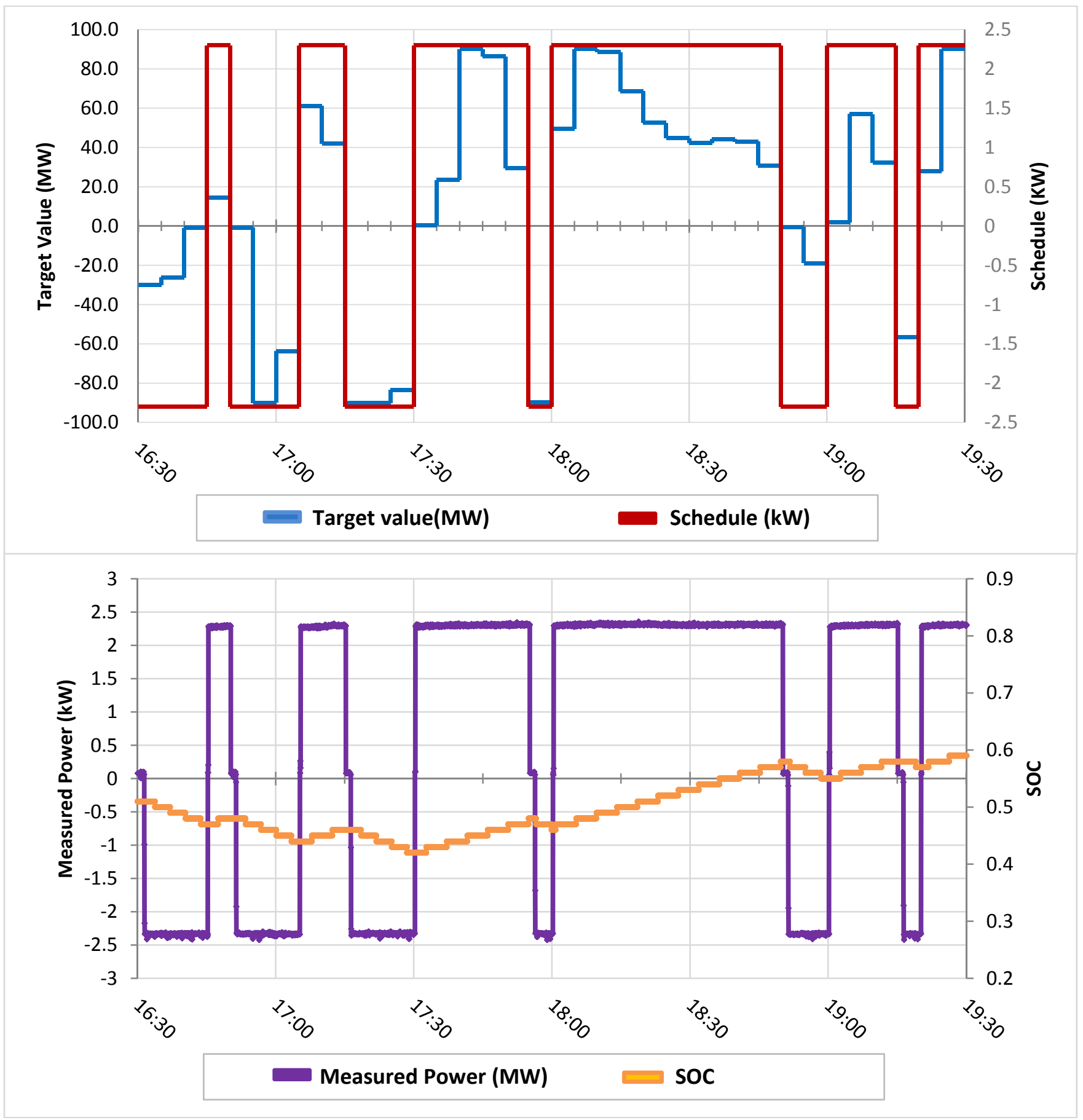

Fig. 10. Test results of EV test bed contribution in regulating power service - Secondary control. (a) Target regulating power of the Danish TSO and VPP generated schedule for the EV test bed and the other EV. (b) Measured power response and battery SOC of EV test bed.

\section{EXPERIMENTAL RESULTS}

The EV test bed participation in regulating power reserves was tested considering the regulating power required for secondary control, by the Danish TSO, on the 1st of January 2009 [25]. The regulating power profile sent from the TSO to the VPP is given in 5-minutes average MW values as shown in Fig. 10(a). The target regulating power is derived by the sum of all up and down regulation requests sent out by the TSO to an array of providers in the same 5-minutes. The target anyway does not reflect the exact need of the system but rather the value is used to drag the providers in the right direction.
Nevertheless, the target value is a very good approximation to the real-time need of regulation reserves.

A new schedule, related to the TSO power target, was generated by the VPP every 5-minutes, and sent to the EV test bed. The regulation was tested in the time interval $16 \mathrm{~h} 30$ to $19 \mathrm{~h} 30$. The schedule is shaped as $\pm 2.3 \mathrm{~kW}$ power requests with time stamps, indicating the activation/deactivation time of charging and V2G mode, Fig. 10(a). Since each EV has a very small capacity compared to the grid needs, it was assumed that the VPP meets the TSO target by aggregating a number of simulated EV. The EV system response, Fig. 10(b), is taken measuring the electric power flow at the point of 
common coupling (PCC) of the EV test bed with the grid. The power was recorded with 1 minute sampling time. Test results are depicted in Fig. 10(b). It is possible to observe that the EV test bed is able to react in real-time to the power schedule sent by the VPP. The measured power profile in Fig. 10(b) validates the effectiveness of the $\mathrm{EV}$ architecture proposed in this work. Furthermore, the SOC profile shows the energy variation in the EV test bed battery, during the regulation service. The EV test bed started to contribute to regulating power service with an initial SOC of about 0.5 or $50 \%$.

\section{CONCLUSIONS}

Testing the capabilities of EV for smart grid applications requires the development of adequate evaluation platforms. In literature it was demonstrated that EV can potentially operate under a number of coordination schemes, including the participation in regulating power reserves. While this was extensively presented by simulation scenarios, in this paper, a real implementation of regulating power reserve performed by a full-scale EV test bed was presented. The test bed was designed to flexibly interact in real-time with an EV coordinator and the electricity grid, under different coordination concepts. To do so, real EV components and communication interfaces were used, that make possible an end-to-end interaction with a VPP. The implementation of an $\mathrm{EV}$ test bed from scratch enabled the management of the single components involved in the EV system: charging/discharging units and BMS. With the implemented communication and control architecture it was possible to establish a stable communication between the EV the test bed and the Virtual Power Plant.

The potential offered by EV for regulating power was demonstrated testing the EV test bed hardware and software interfaces. An array of regulating power requests (load frequency control) within a 3-hours time interval, sent by the Danish TSO on the 1st of January 2009, was used as study case. The TSO target values were converted to an EV compatible schedule by the Edison VPP and sent down to the EV test bed among the other simulated EV. Test results revealed the potential capability of EV to respond in real-time to different charging/discharging requests based on different coordination plans. Further investigations will be performed for evaluating the reliability of the communication involved, when several fleets of EV are simultaneously coordinated.

\section{ACKNOWLEDGMENTS}

The authors would like to thank Sammarco Elettronica, Italy, for the technical support offered in the realization of the Electric Vehicle test bed.

\section{REFERENCES}

[1] J. A. Pecas Lopes, F. Joel Soares, and P. M. Rocha Almeida, "Integration of Electric Vehicles in the Electric Power System", in Proc. IEEE, Vol. 99, 2011

[2] European Commission, "20 20 by 2020 Europe's climate change opportunity", COM (2008) 30 final, Brussels, 2008.
[3] A. Brooks, "Integration of electric drive vehicles with the power grid - a new application for vehicle batteries", in Battery Conference on Applications and Advances. The Seventeenth Annual, 2002.

[4] W. Kempton and J. Tomic, "Vehicle-to-grid power fundamentals: Calculating capacity and net revenue", J. Power Sources, vol. 144, no. 1, pp. 268-279, Jun. 2005.

[5] S. Deilami, A.S. Masoum, P. S. Moses, M. A. S. Masoum, "Real-time coordination of Plug-in Electric Vehicle Charging in Smart Grids to Minimize Power Losses and Improve Voltage Profile", in IEEE Transactions on Smart Grid, Vol. 2, no. 3, pp. 456-467, 2011.

[6] N. Rotering, M. Ilic, "Optimal Charge Control of Plug-in Hybrid Electric Vehicles in Deregulated Electricity Markets", in IEEE Transactions on Power Systems, Vol. 26, no. 3, pp. 1021-1029, 2011.

[7] J. R. Pillai and B. Bak-Jensen, "Vehicle-to-grid systems for frequency regulation in an Islanded Danish distribution network", in IEEE Proc. Vehicle Power and Propulsion Conference (VPPC), 2010.

[8] M. D. Galus, S. Koch, G. Andersson, "Provision of Load Frequency Control by PHEVs, Controllable Loads, and a Cogeneration Unit", in IEEE Transactions on Industrial Electronics, Vol. 58, Nr. 10, 2011.

[9] B. Jansen, C. Binding, O. Sundström, D. Gantenbein, "Architecture and Communication of an Electric Vehicle Virtual Power Plant", in IEEE Proc. First IEEE International Conference on Smart Grid Communications, 2010

[10] C. Binding, D. Gantenbein, B. Jansen, O. Sundstrom, P. B. Andersen, F. Marra, B. Poulsen and C. Træholt, "Electric Vehicle Fleet Integration in the Danish EDISON Project - A Virtual Power Plant on the Island of Bornholm", IEEE Power \& Energy Society General Meeting, 2009.

[11] N. Ruiz, I. Cobelo, J. Oyrzabal, "A Direct Load Control Model for Virtual Power Plant Management", in IEEE Transactions of Power Systems, Vol. 24, No. 2, pp. 959-966, 2009.

[12] J. L. Aguero, M. C. Berequi, F. Issouribehere, "Grid Frequency Control. Secondary frequency control tuning taking into account distributed primary frequency control", in IEEE Proc. of Power and Energy Society General Meeting, 2010.

[13] K. Chen, A. Bouscayrol, A. Berthon, P. Delarue, D. Hissel, and R. Trigui, "Global modeling of different vehicles", IEEE Vehicular Technology Magazine, 2009

[14] B. Lunz, T. Pollok, A. Schnettler, R. W. De Doncker, D. U. Sauer, "Evaluation of Battery Charging Concepts for Electric Vehicles and Plug-in Hybrid Electric Vehicles", Advanced Automotive Battery Conference (AABC), 2009

[15] IEC 61851, Electric vehicle conductive charging system - Electric vehicles requirements for conductive connection of an a.c./d.c. power supply.

[16] P. Morrison, A. Binder, B. Funieru, C. Sabirin, "Drive train design for medium-sized zero emission electric vehicles", 13th European Conference on Power Electronics and Applications, 2009.

[17] General Motors, "Chevrolet Volt - Quick reference sheet", online

[18] Nissan, "Overview of Nissan Leaf", in News Releases, www.nissan-global.com, 2010

[19] Frost \& Sullivan, "M5B6-Global Electric Vehicles Lithium-ion Battery Second Life and Recycling Market Analysis", public report, 2010.

[20] Thunder Sky, Li-ion battery user manual

[21] EDISON project, "WP3 report D3.1", www.edison-net.dk

[22] IEC 61850 Part 7-420

[23] A. Bro Pedersen, E. Bragi Hauksson, P. Bach Andersen, B. Poulsen, C. Træholt, and D. Gantenbein "Facilitating a generic communication interface to distributed energy resources", in IEEE Proc. First IEEE International Conference on Smart Grid Communications, 2010

[24] A. Timbus, M. Larsson, and C. Yuen, "Active Management of Distributed Energy Resources Using Standardized Communications and Modern Information Technologies", in IEEE Transactions on Industrial Electronics, Vol. 56, Nr. 10, pp. 4029-4037, 2009

[25] Energinet.dk, "Load Frequency Control - Secondary Reserve data", January, 2009. 